\title{
The Effectiveness of Tele-education for Health Field University Students as a Learning Method during a COVID-19 Pandemic: A Systematic Review
}

\author{
Laili Rahayuwati(D), Iqbal Pramukti* (D), Raini Diah Susanti (D) \\ Department of Community Health Nursing, Faculty of Nursing, Universitas Padjadjaran, Sumedang, West Java, Indonesia
}

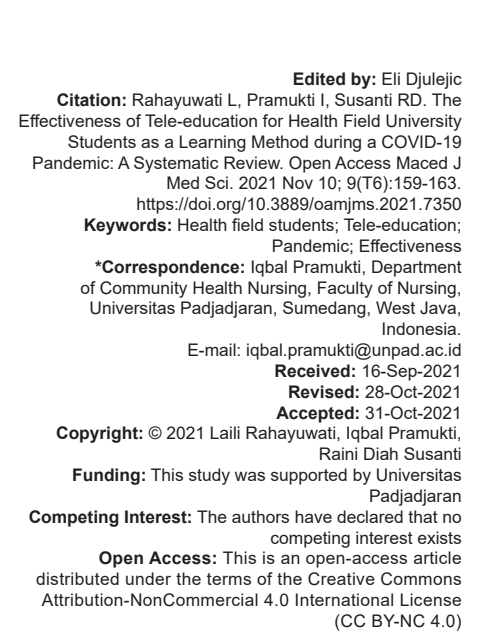

Abstract

BACKGROUND: The COVID-19 pandemic has been affecting many aspects including education globally as many countries closed the school temporally.

AIM: This study aimed to summarize the effectiveness of tele-education application among health field university students.

METHODS: PubMed and EBSCO databases for studies published up to August 2020 were searched. Studies reporting the academic performance or skills performance or students satisfaction were included in the study. Study quality was assessed using the Joanna Briggs Institute appraisal tool.

RESULTS: Published between 2002 and 2020, 22 studies were conducted in developed countries and two studies in developing countries. The tele-education method included e-learning, virtual, and digital learning. When comparing to control group, of 15 studies intervention studies measuring academic performance, seven studies showed a higher mean score among intervention group. For skills performance, there were no studies showing higher skill performance. For studies measuring student' satisfaction, one-third showing higher student' satisfaction among the intervention group compared to the control.

CONCLUSION: Our finding highlighted the positive effect of various tele-education on academic performance among the health field university students. Applying the various tele-education in the learning process for the health field university students during the COVID-19 pandemic is suggested.

\section{Introduction}

The COVID-19 pandemic has been affecting many aspects including education. It may due to the global policy among many countries to close the school temporally to prevent the spreading of the disease [1], [2]. On the severe acute respiratory syndrome epidemic that had been occurred in 2003 , a study stated that many students had been halted due to the outbreak [3]. Therefore, an alternative learning method to overcome the situation is urgently needed.

Tele-education as the application of technology in the delivery of distance learning has been used for decades to facilitate students who lived in remote areas to learn [4]. The main component including audio, video, and computer [4]. However, the effectiveness of this method was unclear. A study in Palestine stated the application of tele-education among medical and nursing students worked at the Gaza territory was effective in achieving the learning outcome [5]. Campbell et al. found that the use of tele-education in diagnosing ophthalmic disease was also effective, however, there was a limitation in controlling the precision of the diagnosis [6].
The variability of conclusive information on the application of tele-education requires additional study. The study aimed to conduct a systematic review to summarize the effectiveness of tele-education applications among medical field university students.

\section{Materials and Methods}

\section{Search strategy}

Using PRISMA guidelines for a systematic review, databases were searched up to August 2020 included PubMed and EBSCO [7]. The terms used in the searches varied according to the database utilized, thus included tele-education, nursing, physician, pharmacy, student, medical, effectiveness, academic performance, student's satisfaction, pandemic, and outbreak.

A study was eligible for inclusion if it included adult health science students reported academic performance and/or student' satisfaction. 
Experimental/clinical trials, cohort, and cross sectional with or without a control group were included in the study. Studies were excluded if they were not in English. Two researchers (LR and IP) independently screened all titles, abstracts, and full texts and appraised study quality. The disagreement was resolved by a third researcher $(R D)$.

\section{Data extraction}

Data extraction included author, year of publication, study location, study design, population, sample size, and demography, intervention type, assessment tools, and measured outcome.

\section{Quality assessment}

Study quality was assessed using the Joanna Briggs Institute critical appraisal checklist tool for randomized control trials (RCTs) studies, nonrandomized, and cohort studies [8]. All tools for each study have four categories of the answer: Yes, no, unclear, and not applicable. The tool for RCT, nonrandomized, and cohort studies consists of 13, nine, and 12 items, respectively.

\section{Results}

Two databases provided 869 articles from the year 1989 to August 2020 (Figure 1). After excluding duplicates, and applying inclusion and exclusion criteria, 126 articles remained. After full-text examination, 26 articles remained for quality appraisal. Most studies met the criteria for the appraisal (Table 1).

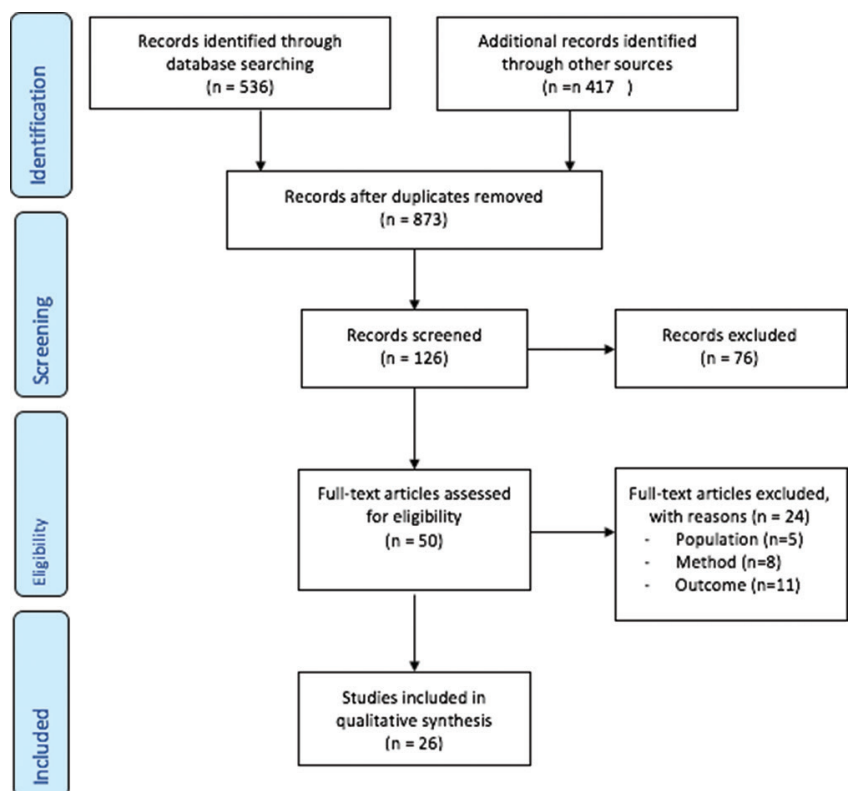

Figure 1: Flow diagram describing article selection

\section{Study characteristic}

Published between 2002 and 2020, 22 studies were conducted in developed countries and two studies in developing countries (Table 1). Published between 2002 and 2020, 22 studies were conducted in developed countries and two studies in developing countries (Table 1), eleven in the United States, two in Egypt, two in Germany, and one each in the United Kingdom, Singapore, Sweden, Norway, Canada, Taiwan, Italy, Spain, Brazil, Iran, and Croatia. RCT design was used by seven studies [9], [10], [11], [12], [13], [14], [15], while 15 studies used quasi-experimental design [16], [17], [18], [19], [20], [21], [22], [23], [24], [25], [26], [27], [28], [29], [30]. Cohort design was used by four studies [31], [32], [33], [34]. The sample size ranged from 9 in Reese experimental study [28] in the USA to 2700 in Aboshady et al. study in Egypt [31] (Table 1). In most studies, the majority of subjects were women. Subject age, provided by 10 studies, ranged from 18.3 (16) to 33.0 (24) years.

\section{Academic performance}

The use of various tele-education showed a various effect on academic performance (Table 2). When comparing to the control group, several studies showed a various mean score of the test in the experimental group including higher, lower, and no significant different. Among seven intervention e-learning studies, four studies showed higher mean score [9], [13], [15], [29], while, one study showed a lower score [16] and two studies showing no significant difference [10], [23]. For virtual learning studies, among five intervention studies, two studies showed higher mean score [17], [25], one study with a lower score [26], and two studies with no significant difference [11], [18]. For digital learning studies, among three intervention studies, only one study showed a higher mean score [22], while, two studies with no significant difference [14], [24].

\section{Skills performance}

The effect of tele-education on skills performance was also documented in several studies (Table 3). When comparing to the control group, among the two intervention e-learning studies, there were no studies showed higher skills performance in the experimental group. One study showed a lower degree of skill performance [16] and one study with no significant difference [10]. For intervention virtual learning studies, there was one study that showed a comparison with no significant difference [18]. For intervention digital learning studies, there was no study provided the comparison.

\section{Student satisfaction}

The effect of tele-education on student satisfaction was also documented in several studies 
Table 1: Characteristic of studies

\begin{tabular}{|c|c|c|c|c|c|c|c|c|c|}
\hline Authors & Country & Study design & $\begin{array}{l}\text { Study fields of } \\
\text { participants }\end{array}$ & Sample size (n) & Exposure $(n)$ & Control (n) & Female (\%) & Period & Age (years) \\
\hline Abdelaziz et al. (2011) [16] & Egypt & Quasi-experimental & Nursing & 276 & 90 & 186 & 63.3 & Non-pandemic & 18.3 \\
\hline Aboshady et al. (2015) [31] & Egypt & Cohort & Medical & 2700 & & & & & \\
\hline Attardi et al. (2018) [17] & Canada & Quasi-experimental & Medical & 491 & 138 & 353 & 51.9 & Non-pandemic & 20.9 \\
\hline Back et al. (2014) [32] & Germany & Cohort & Medical & 147 & 147 & & & & \\
\hline Bello et al. (2005) [18] & Italy & Quasi-experimental & Medical & 56 & 28 & 28 & 60.7 & Non-pandemic & $28.5+1.6$ \\
\hline Bhatti et al. (2011) [9] & USA & RCT & Medical & 148 & 75 & 73 & 53.3 & Non-pandemic & $22(21-27)$ \\
\hline Boye et al. (2012) [19] & Norway & Quasi- experimental & Medical & 84 & 84 & & & Non-pandemic & \\
\hline Chi and Chang (2002) [20] & Taiwan & Quasi- experimental & Medical & 154 & 106 & 48 & & & \\
\hline Cubo et al. (2017) [21] & Spain & Quasi- experimental & Medical & 120 & 120 & & 66.7 & Non-pandemic & \\
\hline Dolan et al. (2015) [10] & UK & RCT & Health science & 22 & 12 & 10 & & Non-pandemic & \\
\hline Gossenheimer et al. (2017) [22] & Brazil & Quasi-experimental & Nursing & 74 & 74 & & 89.3 & Non-pandemic & $23.9(19.0-31.0)$ \\
\hline Graber (2019) [23] & USA & Quasi-experimental & Nursing & 110 & 63 & 47 & & Non-pandemic & \\
\hline Hubble and Richards (2006) [24] & USA & Quasi-experimental & Paramedic & 31 & 21 & 10 & & Non-pandemic & $33(7.1)$ \\
\hline Authors & Country & Study design & Population & Sample size $(n)$ & Exposure $(n)$ & Control (n) & Female (\%) & Period & Age (years) \\
\hline Kidd and Stamatakis (2006) [25] & USA & Quasi-experimental & Pharmacy & 113 & 75 & 38 & & Non-pandemic & $25.6(3.0)$ \\
\hline Klibanov et al. (2018) [26] & USA & Quasi-experimental & Pharmacy & 108 & 16 & 92 & 67.0 & Non-pandemic & $28.0(5.0)$ \\
\hline Kukolja-Taradi et al. (2008) [27] & Croatia & Quasi-experimental & Medical & 68 & 68 & & & Non-pandemic & \\
\hline Libby et al. (2017) [33] & USA & Cohort & Dentistry & 122 & 122 & & 95.6 & Non-pandemic & \\
\hline Mattheos et al. (2003) [11] & Sweden & RCT & Dentistry & 39 & 24 & 15 & & Non-pandemic & \\
\hline Phadtare et al. (2009) [12] & USA \& Brazil & RCT & Medical & 48 & 24 & 24 & 54.2 & Non-pandemic & $23.5(1.5)$ \\
\hline Raupach et al. (2009) [13] & Germany & RCT & Medical & 148 & 74 & 74 & & Non-pandemic & \\
\hline Reese et al. (2009) [28] & USA & Quasi-experimental & Psychology & 9 & 9 & & & Non-pandemic & \\
\hline Sichani et al. (2018) [29] & Iran & Quasi-experimental & Medical & 47 & 47 & & 40.5 & Non-pandemic & $22.5(0.6)$ \\
\hline Solomon et al. (2004) [14] & USA & RCT & Medical & 29 & 17 & 12 & & Non-pandemic & \\
\hline Srinivasan (2020) [34] & Singapore & Cohort & Medical & 16 & 16 & & & $\begin{array}{l}\text { COVID-19 } \\
\text { pandemic }\end{array}$ & \\
\hline Subramanian et al. (2012) [15] & USA & RCT & Medical & 30 & 15 & 15 & & Non-pandemic & \\
\hline Vogt et al. (2010) [30] & USA & Quasi-experimental & Nursing & 52 & 52 & & & Non-pandemic & \\
\hline
\end{tabular}

RCT: Randomized control trial.

(Table 2). When comparing to the control group, among the two intervention e-learning studies, one study showed a higher satisfaction level [12], while one study showed no significant different [23]. For intervention virtual learning studies, one study showed a higher satisfaction level [18], while one study showed no significant difference [28]. For intervention digital learning study, only one study provided the comparison that showed a lower degree of satisfaction in the experimental group [20].

\section{Discussion}

The effectiveness of tele-education on academic performance, skills performance, and satisfaction among health field university students has been documented. Our summary highlights the effect on academic performance as the majority of the included studies showed a positive effect. Nearly half of intervention studies measuring the effect on academic performance showed the increasing mean score. An earlier systematic review study by Chipps et al. [35] found a similar finding, however, the review only focused on virtual learning, while our study included virtual, e-learning, and digital learning. Furthermore, the previous study only found one study supported the positive effect, while our review found seven studies.

The improvement of skills performance on students also has been documented in one-third of studies provided data related. The previous review found a greater percentage of studies showing the improvement of skill performance [36]. The few studies

Table 2: Academic performance, skill performance, and students' satisfaction across the studies $(n=26)$

\begin{tabular}{|c|c|c|c|}
\hline Authors & Academic performance & Skill performance & Satisfaction \\
\hline Abdelaziz et al. (2011) [16] & OG versus CG: $25.8 \pm 8.4$ versus $29.2 \pm 65.6$ ) & OG versus CG: 95.6 versus 96.8 & \\
\hline Aboshady et al. (2015) [31] & & & $84 \%$ of students satisfied \\
\hline Attardi et al. (2018) [17] & OG versus CG: $78.33 \pm 18.81$ versus $77.04 \pm 8.00$ & & \\
\hline Back et al. (2014) [32] & OG versus CG: 73.20 versus 44.00 & & \\
\hline Bello et al. (2005) [18] & no different & No different & OG versus CG: 10.0 versus 9.0 \\
\hline Bhatti et al. (2011) [9] & OG versus CG's increase score: 3.66 versus 3.23 & & \\
\hline Boye et al. (2012) [19] & & & $88 \%$ of students satisfied \\
\hline Chi and Chang (2002) [20] & & & Online was less satisfied than face to face \\
\hline Cubo et al. (2017) [21] & & & Students satisfaction: $51.6 \%$ \\
\hline Dolan et al. (2015) [10] & No different & No different & \\
\hline Gossenheimer et al. (2017) [22] & OG versus CG: 7.7 versus 7.2 & & \\
\hline Graber (2019) [23] & No different & & No different \\
\hline Hubble and Richards (2006) [24] & No different & & \\
\hline Kidd and Stamatakis (2006) [25] & OG versus CG: 3.41 versus 3.25 & & \\
\hline Klibanov et al. (2018) [26] & Distance versus control: $81.5 \pm 9.5$ versus $86.9 \pm 7.1$ & & \\
\hline Kukolja-Taradi et al. (2008) [27] & $97 \%$ of students passed examination & & Most students were satisfied \\
\hline Libby et al. (2017) [33] & & & No different \\
\hline Mattheos et al. (2003) [11] & No different & & \\
\hline Phadtare et al. (2009) [12] & & & Online versus control: $4.3 \pm 0.73$ versus $3.09 \pm 1.11$ \\
\hline Raupach et al. (2009) [13] & $O G$ versus CG: $2.5 \pm 1.1$ versus $2.0 \pm 1.2$ & & \\
\hline Reese et al. (2009) [28] & & & No different \\
\hline Sichani et al. (2018) [29] & OG versus CG: $19.67 \pm 4.63$ versus $17.42 \pm 4.08$ ) & & \\
\hline Solomon et al. (2004) [14] & No different & & \\
\hline Srinivasan (2020) [34] & & & $87.5 \%$ of students satisfied \\
\hline Subramanian et al. (2012) [15] & OG versus CG: $86.7 \pm 2.0$ versus $61.7 \pm 2.0$ & & \\
\hline Vogt et al. (2010) [30] & No different & & $60 \%$ of students were satisfied \\
\hline
\end{tabular}


reporting an improvement among the experimental group in our finding may due to the study design used. Most studies used e-learning which may give less effect on skill performance compare to virtual or digital learning. Furthermore, the potential reason may due to the less effect of tele-education on the skills aspect of the students.

Our study also revealed a high number of studies showing a higher satisfaction level among tele-education students group compared to the traditional lecture. This finding was higher than earlier systematic review reporting only one-sixth of studies with higher satisfaction [36].

The important finding in our study was the positive effect of various type of tele-education on academic performance as shown by the majority of the included studies. The finding shown by each type of tele-education may provide the benefit of using tele-education in several methods among health field university students, particularly during the COVID-19 pandemic. The selection of methods is important in a pandemic situation as many students may be halted due to national protocol. Providing several effective types of tele-education may prevent further disturbance in the learning process.

The limitation found in our study included the lack of studies conducted during the COVID-19 period. It may due to the disturbance of data collection during that time as many countries worldwide applied lockdown during the crisis. However, we believe the various trials with various types of tele-education may overcome the limitation found. Further study in comparing the effectiveness of tele-education during the pandemic era and non-pandemic era may be needed.

\section{Conclusion}

Our finding highlighted the positive effect of various tele-education on academic performance among the health field university students. Applying the various tele-education in the learning process for health field university students during the COVID-19 pandemic is suggested.

\section{References}

1. UNESCO. COVID-19 Educational Disruption and Response, France; 2020.

2. Varalakshmi R, Swetha R. COVID 2019-role of faculty members to keep mental activeness of students. Asian J Psychiatr. 2020;51:102091. https://doi.org/10.1016/j.ajp.2020.102091

PMid:32344332
3. Loh LC, Ali AM, Ang TH, Chelliah A. Impact of a spreading epidemic on medical students. Malays $J$ Med Sci. 2006;13(2):30-6.

PMid:22589602

4. Curran VR. Tele-education. J Telemed Telecare. 2006;12(2):57-63.

PMid: 16539750

5. Ghanem AM, Zaben M, Shaban NA, Green C, Abu-Sitta G, Myers S. Tele-education for teaching of evidence-based medicine and burn care in the occupied Palestinian territory: A pilot study. Lancet. 2012;380:S28-9. https://doi.org/10.1016/ s0140-6736(13)60208-1

6. Campbell JP, Swan R, Jonas K, Ostmo S, Ventura CV, Martinez-Castellanos MA, et al. Implementation and evaluation of a tele-education system for the diagnosis of ophthalmic disease by international trainees. AMIA Annu Symp Proc. 2015;2015:366-75.

PMid:26958168

7. Liberati A, Altman DG, Tetzlaff J, Mulrow C, Gøtzsche PC, loannidis JP, et al. The PRISMA statement for reporting systematic reviews and meta-analyses of studies that evaluate healthcare interventions: Explanation and elaboration. BMJ. 2009;339:b2700. https://doi.org/10.1136/bmj.b2700 PMid:19622552

8. JBI. The Joanna Briggs Institute Critical Appraisal tools for use in JBI Systematic Reviews; 2017. https://doi.org/10.11124/ jbisrir-2016-002421

9. Bhatti I, Jones K, Richardson L, Foreman D, Lund J, Tierney G. E-learning vs lecture: Which is the best approach to surgical teaching? Colorectal Dis. 2011;13(4):459-62. https://doi. org/10.1111/j.1463-1318.2009.02173.x PMid:20041922

10. Dolan E, Hancock E, Wareing A. An evaluation of online learning to teach practical competencies in undergraduate health science students. Internet High Educ. 2015;24:21-5. https://doi. org/10.1016/j.ineduc.2014.09.003

11. Mattheos N, Nattestad A, Attström R. Feasibility of and satisfaction with the use of low-bandwidth videoconferencing for examination of undergraduate students. J Telemed Telecare. 2003;9(5):278-81. https://doi. org/10.1258/135763303769211292

PMid:14599331

12. Phadtare A, Bahmani A, Shah A, Pietrobon R. Scientific writing: A randomized controlled trial comparing standard and on-line instruction. BMC Med Educ. 2009;9:27. https://doi. org/10.1186/1472-6920-9-27

PMid: 19473511

13. Raupach $T$, Muenscher $C$, Anders $S$, Steinbach R, Pukrop $T$, Hege I, et al. Web-based collaborative training of clinical reasoning: A randomized trial. Med Teach. 2009;31(9):e431-7. https://doi.org/10.1080/01421590903095502

PMid: 19811180

14. Solomon DJ, Ferenchick GS, Laird-Fick HS, Kavanaugh K A randomized trial comparing digital and live lecture formats [ISRCTN40455708]. BMC Med Educ. 2004;4:27. https://doi. org/10.1186/1472-6920-4-27 PMid:15569389

15. Subramanian A, Timberlake M, Mittakanti H, Lara M, Brandt ML. Novel educational approach for medical students: Improved retention rates using interactive medical software compared with traditional lecture-based format. J Surg Educ. 2012;69(2):253-6. https://doi.org/10.1016/j.jsurg.2011.12.007 PMid:22365876

16. Abdelaziz M, Kamel SS, Karam O, Abdelrahman A. Evaluation of E-learning program versus traditional lecture instruction 
for undergraduate nursing students in a faculty of nursing. Teach Learn Nurs. 2011;6(2):50-8. https://doi.org/10.1016/j. teln.2010.10.003

17. Attardi SM, Barbeau ML, Rogers KA. Improving online interactions: Lessons from an online anatomy course with a laboratory for undergraduate students. Anat Sci Educ. 2018;11(6):592-604. https://doi.org/10.1002/ase.1776 PMid:29493909

18. Bello G, Pennisi MA, Maviglia R, Maggiore SM, Bocci MG, Montini $L$, et al. Online vs live methods for teaching difficult airway management to anesthesiology residents. Intensive Care Med. 2005;31(4):547-52. https://doi.org/10.1007/ s00134-005-2561-0

PMid: 15754200

19. Boye S, Moen T, Vik T. An E-learning course in medical immunology: Does it improve learning outcome? Med Teach. 2012;34(9):e649-53. https://doi.org/10.3109/01421 59x.2012.675456

PMid:22497322

20. Chi $\mathrm{CH}$, Chang I. Realtime telemedicine for teaching a firstaid course. J Telemed Telecare. 2002;8(1):36-40. https://doi. org/10.1258/1357633021937442

PMid:11809083

21. Cubo E, Doumbe J, López E, Lopez GA, Gatto E, Persi G, et al. Telemedicine enables broader access to movement disorders curricula for medical students. Tremor Other Hyperkinet Mov (N Y). 2017;7:501. https://doi.org/10.5334/tohm.347 PMid:29123943

22. Gossenheimer AN, Bem T, Carneiro ML, de Castro MS. Impact of distance education on academic performance in a pharmaceutical care course. PLoS One. 2017;12(4):e0175117. https://doi.org/10.1371/journal.pone.0175117 PMid:28384362

23. Graber J EDD, APRN, PMHCNS-BC. Comparison of mental health nursing student academic achievement and satisfaction: Classroom versus online education in teaching therapeutic crisis management techniques. Issues Ment Health Nurs. 2019;40(3):247-51. https://doi.org/10.1080/01612840.2018.150 5985

PMid:30412433

24. Hubble MW, Richards ME. Paramedic student performance: Comparison of online with on-campus lecture delivery methods. Prehosp Disaster Med. 2006;21(4):261-7. https://doi. org/10.1017/s1049023x00003800

\section{PMid: 17076427}

25. Kidd RS, Stamatakis MK. Comparison of students' performance in and satisfaction with a clinical pharmacokinetics course delivered live and by interactive videoconferencing. Am J Pharm Educ. 2006;70(1):10. https://doi.org/10.5688/aj700110 PMid: 17136153

26. Klibanov OM, Dolder C, Anderson K, Kehr HA, Woods JA. Impact of distance education via interactive videoconferencing on students' course performance and satisfaction. Adv Physiol Educ. 2018;42(1):21-5. https://doi.org/10.1152/ advan.00113.2016

PMid:29341811
27. Kukolja-Taradi S, Dogas Z, Dabić M, Perić ID. Scaling-up undergraduate medical education: Enabling virtual mobility by online elective courses. Croat Med J. 2008;49(3):344-51. https://doi.org/10.3325/cmj.2008.3.344

PMid:18581612

28. Reese RJ, Aldarondo F, Anderson CR, Lee SJ, Miller TW, Burton D. Telehealth in clinical supervision: A comparison of supervision formats. J Telemed Telecare. 2009;15(7):356-61. https://doi.org/10.1258/jtt.2009.090401

PMid: 19815905

29. Sichani MM, Mobarakeh SR, Omid A. The effect of distance learning via SMS on academic achievement and satisfaction of medical students. J Educ Health Promot. 2018;7:29. https://doi. org/10.4103/jehp.jehp_116_16

PMid:29629390

30. Vogt M, Schaffner B, Ribar A, Chavez R. The impact of podcasting on the learning and satisfaction of undergraduate nursing students. Nurse Educ Pract. 2010;10(1):38-42. https:// doi.org/10.1016/j.nepr.2009.03.006

PMid: 19781997

31. Aboshady OA, Radwan AE, Eltaweel AR, Azzam A, Aboelnaga $A A$, Hashem HA, et al. Perception and use of massive open online courses among medical students in a developing country: Multicentre cross-sectional study. BMJ Open. 2015;5(1):e006804. https://doi.org/10.1136/ bmjopen-2014-006804

PMid:25564149

32. Back DA, Haberstroh N, Sostmann K, Schmidmaier G, Putzier M, Perka C, et al. High efficacy and students' satisfaction after voluntary vs mandatory use of an E-learning program in traumatology and orthopedics-a follow-up study. J Surg Educ. 2014;71(3):353-9. https://doi.org/10.1016/j.jsurg.2013.11.007 PMid:24797851

33. Libby LA, Boyd LD, Perry KR, Dominick C. Assessing student satisfaction with face-to-face synchronous distance education in a dental hygiene program. J Dent Educ. 2017;81(3):287-92. https://doi.org/10.1002/j.0022-0337.2017.81.3.tb06273.x PMid:28250034

34. Srinivasan DK. Medical students' perceptions and an anatomy teacher's personal experience using an E-learning platform for tutorials during the COVID-19 crisis. Anat Sci Educ. 2020;13(3):318-9. https://doi.org/10.1002/ase.1970 PMid:32374937

35. Chipps J, Brysiewicz P, Mars M. A systematic review of the effectiveness of videoconference-based tele-education for medical and nursing education. Worldviews Evid Based Nurs. 2012;9(2):78-87. https://doi. org/10.1111/j.1741-6787.2012.00241.x PMid:22409341

36. George PP, Papachristou N, Belisario JM, Wang W, Wark PA, Cotic Z, et al. Online eLearning for undergraduates in health professions: A systematic review of the impact on knowledge, skills, attitudes and satisfaction. J Glob Health. 2014;4(1):010406. https://doi.org/10.7189/jogh.04.010406 PMid:24976965 